\title{
THE MECHANISM OF STATE REGISTRATION OF THE RIGHTS TO IMMOVABLE PROPERTY
}

\author{
Yuliya A. Tymchuk \\ Volgograd State University, Volgograd, Russian Federation
}

Introduction: at present, the domestic civil circulation of immovable property is characterized by instability. One of the factors that give rise to this negative phenomenon is the long-standing problem of the reliability of the immovable property rights register.

The degree of reliability of the immovable property rights register is essential for the subjects of civil circulation, who have the right to rely on the information contained in it, without fear of their invalidity.

At the same time, the analysis of the judicial practice shows an increase in the number of disputes on challenging the registered rights to immovable property. The approach formed in the judicial practice, according to which the purchaser of immovable property is obliged to commit actions aimed at checking the property, given that in the presence of the specially authorized bodies, the subject of civil circulation should not take solely the risks associated with the deprivation of the ownership of the acquired property, raises questions. However, in the conditions of the informatization of society, the authorities carry out the search of optimal methods of minimization of risks of the subjects of immovable property civil circulation through the introduction of innovative tools for solving the reliability problem of the immovable property rights register. In this regard, the main purpose of this study is to determine the prospects for the use of innovative tools in the framework of the state registration of the rights to immovable property, as well as their ability to solve the problem of information reliability of the state immovable property register. Methods: the study used both the general scientific methods (the dialectical method of cognition, analysis, synthesis, the formal logical method, etc.) and the specific scientific methods (formal legal, analytical, etc.). Results: the paper assesses the implementation of the principle of reliability of the state rights register at the present stage, as well as the author's point of view on the possibility of using the innovative technologies in the framework of the state registration of rights. The author proves that the introduction of the blockchain technology in the activities of Rosreestr will not completely solve the problem of reliability of the EGRN data. Conclusions: the study revealed the need to create additional mechanisms for data verification at the stage of data entry into the blockchain. In addition, the need to develop the administrative regulations for certain registration actions in case of a positive decision to conduct an experiment on the introduction of the blockchain technology in the EGRN is emphasized.

Key words: principle of public reliability, Unified State Register of Immovable Property, bona fide purchaser, electronic service, blockchain.

Citation. Tymchuk Yu.A. The Mechanism of State Registration of the Rights to Immovable Property. Legal Concept, 2018, vol. 17, no. 4, pp. 53-59. DOI: https://doi.org/10.15688/lc.jvolsu.2018.4.7

УДК $347.22 .02+004.91$

Дата получения статьи: 16.10 .2018

ББК 67.404

Дата принятия статьи: 22.10.2018

\section{ИННОВАЦИОННЫЕ ПОДХОДЫ В ПРАВОВОМ РЕГУЛИРОВАНИИ МЕХАНИЗМА ГОСУДАРСТВЕННОЙ РЕГИСТРАЦИИ ПРАВ НА НЕДВИЖИМОЕ ИМУЩЕСТВО}

\author{
Юлия Александровна Тымчук \\ Волгоградский государственный университет, г. Волгоград, Российская Федерация
}


Введение: в настоящее время отечественный гражданский оборот недвижимости характеризуется нестабильностью. Одним из факторов, порождающих указанное негативное явление, выступает существующая на протяжении длительного времени проблема достоверности реестра прав на недвижимое имущество.

Степень достоверности реестра прав на недвижимое имущество имеет существенное значение для субъектов гражданского оборота, которые вправе полагаться на сведения, содержащиеся в нем, не опасаясь их недействительности.

Вместе с тем анализ судебной практики свидетельствует о росте числа споров об оспаривании зарегистрированных прав на недвижимое имущество. Вызывает вопросы и подход, сформировавшийся в судебной практике, в соответствии с которым на приобретателя недвижимости возлагаются обязанности по совершению действий, направленных на проверку объекта недвижимости, учитывая, что в условиях наличия специально уполномоченных на это органов субъект гражданского оборота не должен брать исключительно на себя риски, связанные с лишением права собственности на приобретаемый объект недвижимости. Однако в условиях информатизации общества органами власти осуществляется поиск оптимальных способов минимизации рисков субъектов гражданского оборота недвижимости посредством внедрения инновационных инструментов для решения проблемы достоверности реестра прав на недвижимое имущество. В связи с этим основной целью настоящего исследования выступает определение перспектив использования инновационных инструментов в рамках механизма государственной регистрации прав на недвижимость, а также их возможностей для решения проблемы достоверности сведений государственного реестра недвижимости. Методы: в ходе исследования были использованы как общенаучные методы (диалектический метод познания, анализ, синтез, формально-логический метод и др.), так и частнонаучные методы (формально-юридический, аналитический и др.). Результаты: в работе дана оценка реализации принципа достоверности государственного реестра прав на современном этапе, а также сформулирована авторская позиция по вопросу о возможностях использования инновационных технологий в рамках механизма государственной регистрации прав. Автор доказывает, что внедрение технологии блокчейн в деятельность Росреестра не позволит полностью решить проблему достоверности данных ЕГРН. Выводы: в результате проведенного исследования выявлена необходимость создания дополнительных механизмовдля верификации данных на этапе ввода сведений в блокчейн. Кроме того, подчеркивается потребность в разработке административного регламента совершения отдельных регистрационных действий в случае принятия положительного решения о проведении эксперимента по внедрению технологии блокчейн в ЕГРН.

Ключевые слова: принцип публичной достоверности, Единый государственный реестр недвижимости, добросовестный приобретатель, электронный сервис, блокчейн.

Цитирование. Тымчук Ю. А. Инновационные подходы в правовом регулировании механизма государственной регистрации прав на недвижимое имущество // Legal Concept = Правовая парадигма. - 2018. - T. 17, № 4. - C. 53-59. - DOI: https://doi.org/10.15688/lc.jvolsu.2018.4.7

\section{Введение}

Анализ практики показывает, что в настоящее время реализация отдельных принципов государственной регистрации прав на имущество, закрепленных в ст. 8.1 ГК РФ, осуществляется на уровне, не обеспечивающем должную защиту имущественных прав субъектов гражданского оборота.

В частности, особого внимания заслуживает принцип достоверности (иначе - публичной достоверности) реестра [1, с. 125].

Исходя из того, что по смыслу п. 5 ст. 1 Федерального закона от 13.07.2015 № 218-Ф3 «О государственной регистрации недвижимости», п. 6 ст. 8.1 ГК РФ запись в Едином государственном реестре недвижимости (далее ЕГРН) не гарантирует собственнику недви- жимости неоспоримости его прав, остро встает проблема защиты добросовестных лиц: добросовестного приобретателя и добросовестного собственника, который не отчуждал свою недвижимость, но лишился ее [4, с. 31].

В судебной практике сложился подход, согласно которому суды, разрешая вопрос о добросовестности приобретателя недвижимости, учитывали не только наличие записи в Едином государственном реестре прав на недвижимое имущество и сделок с ним о праве собственности отчуждателя имущества, но и то, была ли проявлена гражданином разумная осмотрительность при заключении сделки, какие меры принимались им для выяснения прав лица, отчуждающего это имущество, и т. д. [6].

Указанный подход, по справедливому замечанию Р.С. Бевзенко, ставит под сомнение 
фактически всю деятельность Росреестра и необходимость его существования [2]. С этим сложно не согласиться.

Данные судебной статистики свидетельствуют о росте числа споров по искам, связанным с оспариванием зарегистрированных прав на недвижимое имущество. Так, за 2016 г. общее количество поступивших исков данной категории составляет 1723 [12], в то время как за аналогичный период 2017 г. их число выросло до 4304 [13].

Представляется, что для эффективно функционирующей системы государственной регистрации принцип публичной достоверности реестра должен предполагать гарантированность со стороны государства действительности зарегистрированных прав, наличие ограниченной возможности их судебного оспаривания, а в случае установления недействительности этих прав должна быть установлена материальная ответственность государства, которая в настоящее время фактически отсутствует.

Кроме того, возникает вопрос о том, почему при наличии специально созданных государством органов субъект гражданского оборота должен брать на себя риск лишения права собственности на недвижимость по причине недостатков, которые присущи деятельности таких органов, и при этом нести убытки, которые не будут возмещены.

\section{Вектор на цифровизацию механизма государственной регистрации прав на недвижимое имущество}

В целях минимизации обозначенных негативных тенденций, а также в рамках реализации п. 1.3, 1.12 программы «Цифровая экономика Российской экономики» [9] был проведен ряд мероприятий.

Однако прежде следует отметить, что в 2017 г. законодательство о государственной регистрации прав претерпело существенные изменения [14]. Так, 1 января 2017 г. вступил в силу новый Федеральный закон от 13.07.2015 № 218-Ф3 «О государственной регистрации недвижимости» (далее - Закон № 218-Ф3), который ввел электронный Единый государственный реестр недвижимости (ЕГРН), состоящий из реестра объектов недвижимости, реестра прав, ограничений прав и обременений недвижимого имущества, реестра сведений о границах зон с особыми условиями использования территорий, территориальных зон и др., реестровых дел, кадастровых карт, книг учета документов (ст. 7 Закона № 218-ФЗ).

Кроме того, еще до утверждения обозначенной программы и вступления в силу Закона № 218-Ф3 1 июня 2015 г. был запущен электронный сервис по подаче заявления на государственную регистрацию прав в электронном виде.

Безусловно, результатом введения ЕГРН, перехода на электронный документооборот должно стать повышение качества государственных услуг и в целом эффективности деятельности Росреестра, что, в свою очередь, отразится на гражданском обороте недвижимости.

Вместе с тем специалисты отмечают, что в настоящее время предусмотренный Распоряжением Правительства РФ от 01.12.2012 № 2236-р план мероприятий («дорожная карта») «Повышение качества государственных услуг в сфере государственного кадастрового учета недвижимого имущества и государственной регистрации прав на недвижимое имущество и сделок с ним» реализуется не в полной мере. Кроме того, внедрение в регионах ЕГРН происходит с большими трудностями [7], в последнее время нередки и сбои в работе системы [10]. Немаловажно и то, что при работе любой подобной информационной системы не исключены факты несанкционированного внесения изменений в данные как сотрудниками Росреестра (коррупционный фактор), так и в результате хакерских атак.

Из этого следует, что провести оценку эффективности государственного электронного реестра возможно лишь через несколько лет.

\section{Блокчейн \\ как инновационный инструмент обеспечения достоверности данных ЕГРН}

В настоящее время Росреестр, являясь участником пилотного проекта по внедрению технологии блокчейн, проводит работу по определению возможней его использования [11]. 
Так, в целях создания необходимых правовых условий для использования технологии блокчейн был разработан проект постановления Правительства РФ «О проведении на территории г. Москвы эксперимента по использованию технологии "Блокчейн" в целях мониторинга достоверности сведений Единого государственного реестра недвижимости», который в настоящее время размещен на федеральном портале проектов нормативных правовых актов [8]. Обозначенная инициатива является первой попыткой нормативной регламентации использования рассматриваемого инструмента.

В числе ключевых целей использования технологии блокчейн, согласно проекту постановления, обозначены такие, как повышение уровня доверия потребителей государственных услуг к сфере, связанной с оборотом объектов недвижимого имущества, и повышение гарантий защиты права собственности граждан и юридических лиц на объекты недвижимого имущества, расположенные на территории г. Москвы.

Предполагаемый срок реализации эксперимента - с 1 января по 1 июля 2018 года. Учитывая, что на момент написания настоящей работы проект постановления не принят, сроки реализации эксперимента, вероятно, будут скорректированы.

По итогам проведенного эксперимента планируется сделать окончательные выводы о возможности использования данной технологии.

На наш взгляд, внедрение технологии блокчейн позволит решить проблему достоверности данных ЕГРН лишь отчасти.

Действительно, с технической точки зрения возможность внедрения и несанкционированного внесения изменений в сведения, которые стали частью отдельного блока, крайне затруднительна. Поэтому с данных позиций справедливыми выглядят суждения большинства авторов о том, что блокчейн позволит обеспечить или вовсе гарантирует достоверность данных [3; 5, с. 21].

Полагаем, что исследователи, отстаивающую подобную позицию, излишне абсолютизируют возможности технологии блокчейн. Стоит обратить внимание на то, что изначально сведения в блокчейн вносятся человеком, что, в свою очередь, не исключает возмож- ности ее изменения им на самом первом этапе. Исходя из этого требуется разработка дополнительных механизмов проверки вводимой должностным лицом информации, что в целом приведет к увеличению издержек на содержание системы.

\section{Выводы}

Проведенный анализ показал, что за последние несколько лет уполномоченными органами были предприняты определенные шаги, направленные на решение проблемы достоверности реестра прав на недвижимое имущество, в числе которых создание нового реестра прав на недвижимое имущество, а также электронных сервисов для удобства субъектов гражданского оборота.

Вместе с тем проблема достоверности реестра прав на недвижимость продолжает оставаться фактором, негативно влияющим на имущественные права субъектов гражданского оборота, о чем свидетельствуют данные судебной статистики об оспаривании зарегистрированных прав на недвижимость.

В настоящее время перспективным инструментом для решения проблемы достоверности данных ЕГРН является технология блокчейн.

Несмотря на многочисленные преимущества обозначенной технологии, а также ее поддержку, как стороны представителей научного сообщества, так и органов государственной власти, считаем, что ее использование в деятельности Росреестра не позволит полностью решить проблему достоверности данных реестра прав на недвижимое имущество ввиду наличия рисков на этапе ввода информации в систему, для устранения которых имеется объективная необходимость в разработке дополнительного механизма верификации вводимых данных.

Полагаем, что в случае принятия положительного решения о проведении эксперимента по внедрению технологии блокчейн в ЕГРН на территории г. Москвы потребуется разработать соответствующий регламент работы, устанавливающий порядок проведения конкретных административных процедур с учетом специфики обозначенного инновационного инструмента. 


\section{СПИСОК ЛИТЕРАТУРЫ}

1. Алексеев, В. А. Публичная достоверность реестра прав на недвижимость: действующий принцип или дело будущего? / В. А. Алексеев // Закон. 2016. -№ 11.- С. 125-132.

2. Бевзенко, Р. С. Регистрация прав на недвижимое имущество: новый закон и старые проблемы / Р. С. Бевзенко //Академия юриста компании. Электрон. текстовые дан. - Режим доступа: http:// www.uracademy.ru/video.php?vid=22793 (дата обращения: 04.10.2017). - Загл. с экрана.

3. Грушин, И. Ю. BlockChain - решение проблем регистрации недвижимости / И. Ю. Грушин // Московский экономический журнал. - 2018. - № 2. Электрон. текстовые дан. - Режим доступа: http://je.su/ ekonomika-apk/moskovskij-ekonomicheskij-zhurnal-22018-5/?print=pdf (дата обращения: 01.09.2018). - Загл. с экрана.

4. Демкина, А. В. Проблема обеспечения достоверности ЕГРН и защиты добросовестного приобретателя недвижимого имущества / А. В. Демкина, Е. В. Бадулина // Нотариус. - 2016. - № 1. - С. 29-33.

5. Дмитриева, О. А. Технологии «единое окно» и «блокчейн» как пути совершенствования межведомственного информационно-технического взаимодействия / О. А. Дмитриева // Таможенное дело. - 2017. - № 3. - С. 18-21.

6. Обзор судебной практики по делам, связанным с истребованием жилых помещений от добросовестных приобретателей, по искам государственных органов и органов местного самоуправления : (утв. Президиумом Верховного Суда РФ 01.10.2014) // Бюллетень Верховного Суда РФ. - 2015. - № 2.

7. Проблемы межведомственного взаимодействия и сбои в системе ЕГРН тормозят регистрацию собственности //Агентство стратегических инициатив. - Электрон. текстовые дан. - Режим доступа: https://asi.ru/news/91130/ (дата обращения: 01.09.2018 г.). - Загл. с экрана.

8. Проект постановления Правительства РФ «О проведении на территории г. Москвы эксперимента по использованию технологии "Блокчейн" в целях мониторинга достоверности сведений Единого государственного реестра недвижимости» // Федеральный портал проектов нормативных правовых актов. - Электрон. текстовые дан. - Режим доступа: http://regulation.gov.ru/projects\#npa=74195 (дата обращения: 02.10.2018). - Загл. с экрана.

9. Распоряжение Правительства РФ от 28.07.2017 № 1632-р «Об утверждении программы “Цифровая экономика Российской Федерации”» //Собрание законодательства РФ. - 2017. - № 32 (07 авг.).-Ст. 5138.

10. Росреестр не может оправиться от сбоя в системе // Коммерсанть. - Электрон. текстовые дан. - Режим доступа: https:/www.kommersant.ru/ doc/3727200 (дата обращения: 31.08.2018). - Загл. с экрана.

11. Росреестр принял участие в заседании рабочей группы по внедрению блокчейн // Росреестр : [офиц. сайт]. - Электрон. текстовые дан. - Режим доступа: https://rosreestr.ru/site/press/news/rosreestrprinyal-uchastie-v-zasedanii-rabochey-gruppy-povnedreniyu-blokcheyn/?sphrase id=7143882 (дата обращения: 05.10.2017). - Загл. с экрана.

12. Сводные статистические сведения о деятельности федеральных судов общей юрисдикции и мировых судей за 2016 год // Судебный департамент при Верховном суде РФ. Данные судебной статистики. - Электрон. текстовые дан. - Режим доступа: http://www.cdep.ru/index.php?id=79\&item=3832 (дата обращения: 16.01.2018). - Загл. с экрана.

13. Сводные статистические сведения о деятельности федеральных судов общей юрисдикции и мировых судей за 2017 год // Судебный департамент при Верховном суде РФ. Данные судебной статистики. - Электрон. текстовые дан. - Режим доступа: http://www.cdep.ru/index.php?id=79\&item=4476 (дата обращения: 01.03.2018). - Загл. с экрана.

14. Тымчук, Ю. А. Новый вектор развития законодательства о государственной регистрации прав на недвижимость: от бумажных свидетельств до блокчейна / Ю. А. Тымчук // Международный студенческий научный вестник. - 2017. - № 5. Электрон. текстовые дан. - Режим доступа: http:// eduherald.ru/ru/article/view?id=17745 (дата обращения: 08.09.2018). - Загл. с экрана.

\section{REFERENCES}

1. Alekseev V.A. Publichnaya dostovernost reestra prav na nedvizhimost: deystvuyushchiy printsip ili delo budushchego? [Public Reliability of the Register of Rights to the Real Estate: Current Principle or Business of the Future?]. Zakon, 2016, no. 11 , pp. 125-132.

2. Bevzenko R.S. Registratsiya prav na nedvizhimoe imushchestvo: novyy zakon i starye problemy [Registration of the Rights to Real Estate: New Law and Old Problems]. Akademiya yurista kompanii [Academy of Company's Lawyer]. URL: http://www.uracademy.ru/video.php?vid=22793 (accessed 4 October 2017).

3. Grushin I.Yu. BlockChain - reshenie problem registratsii nedvizhimosti [BlockChain is the Solution of Problems of Real Estate Registration]. Moskovskiy ekonomicheskiy zhurnal, 2018, no. 2. URL: http:// qje.su/ekonomika-apk/moskovskij-ekonomicheskijzhurnal-2-2018-5/?print=pdf (accessed 1 September 2018). 
4. Demkina A.V., Badulina E.V. Problema obespecheniya dostovernosti EGRN i zashchity dobrosovestnogo priobretatelya nedvizhimogo imushchestva [The Problem of Ensuring Reliability of EGRN and Protection of the Conscientious Purchaser of Real Estate]. Notarius, 2016, no. 1, pp. 29-33.

5. Dmitrieva O.A. Tekhnologii «edinoe okno» i «blokcheyn» kak puti sovershenstvovaniya mezhvedomstvennogo informatsionno-tekhnicheskogo vzaimodeystviya ["Uniform Window" and "Blockchain" Technologies as a Way to Improve Interdepartmental Information and Technical Interaction]. Tamozhennoe delo, 2017, no. 3, pp. 18-21.

6. Obzor sudebnoy praktiki po delam, svyazannym s istrebovaniem zhilykh pomeshcheniy ot dobrosovestnykh priobretateley, po iskam gosudarstvennykh organov i organov mestnogo samoupravleniya: (utv. Prezidiumom Verkhovnogo Suda RF 01.10.2014) [The Review of Juricial Practice on the Cases Connected with Reclamation of Premises from Conscientious Purchasers on Claims of Public Authorities and Local Governments (Approved by Presidium of the Supreme Court of the Russian Federation on 1 October 2014)]. Byulleten Verkhovnogo Suda RF, 2015, no. 2.

7. Problemy mezhvedomstvennogo vzaimodeystviya i sboi $v$ sisteme EGRN tormozyat registratsiyu sobstvennosti [Problems of Interdepartmental Interaction and Failures in the EGRN System Slow down Registration of Property]. Agentstvo strategicheskikh initsiativ [Agency of Strategic Initiatives]. URL: https://asi.ru/news/ 91130/ (accessed 1 September 2018).

8. Proekt postanovleniya Pravitelstva RF «O provedenii na territorii g. Moskvy eksperimenta po ispolzovaniyu tekhnologii "Blokcheyn" $v$ tselyakh monitoringa dostovernosti svedeniy Edinogo gosudarstvennogo reestra nedvizhimosti» [Draft Resolution of the Government of the Russian Federation "The Experimental Use of Blockchain Technology in Moscow for Monitoring Reliability of Data of the Unified State Register of the Real Estate"]. Federalnyy portal proektov normativnykh pravovykh aktov [Federal Portal of Draft Regulations]. URL: http:/ /regulation.gov.ru/projects\#npa=74195 (accessed 2 October 2018).

9. Rasporyazhenie Pravitelstva RF ot 28.07.2017 № 1632-r «Ob utverzhdenii programmy “Tsifrovaya ekonomika Rossiyskoy Federatsii"» [Order of the
Government of the Russian Federation of 28 July 2017 No. 1632-r "About Approval of the Program 'Digital Economy of the Russian Federation"']. Sobranie zakonodatelstva RF [Collected Legislation of the Russian Federation], 2017, no. 32, art. 5138.

10. Rosreestr ne mozhet opravitsya ot sboya $\mathrm{v}$ sisteme [The Federal Registration Service Cannot Recover from Failure in System]. Kommersant. URL: https://www.kommersant.ru/doc/3727200 (accessed 31 August 2018).

11. Rosreestr prinyal uchastie $\mathrm{v}$ zasedanii rabochey gruppy po vnedreniyu blokcheyn [The Federal Registration Service Participated in a Session of the Working Group on Introduction of a Blockchain]. Rosreestr [Federal Registration Service]. URL: https://rosreestr.ru/site/press/news/rosreestrprinyal-uchastie-v-zasedanii-rabochey-gruppy-povnedreniyu-blokcheyn/?sphrase_id $=7143882$ (accessed 5 October 2017).

12. Svodnye statisticheskie svedeniya o deyatelnosti federalnykh sudov obshchey yurisdiktsii i mirovykh sudey za 2016 god [Summary Statistical Data on Activity of Federal Courts of General Jurisdiction and Magistrates for 2016]. Sudebnyy departament pri Verkhovnom sude RF. Dannye sudebnoy statistiki [Judicial Department at the Supreme Court of the Russian Federation. Data of Judicial Statistics]. URL: http://www.cdep.ru/ index.php?id=79\&item=3832 (accessed 16 January 2018).

13. Svodnye statisticheskie svedeniya o deyatelnosti federalnykh sudov obshchey yurisdiktsii i mirovykh sudey za 2017 god [Summary Statistical Data on Activity of Federal Courts of General Jurisdiction and Magistrates for 2017]. Sudebnyy departament pri Verkhovnom sude RF. Dannye sudebnoy statistiki [Judicial Department at the Supreme Court of the Russian Federation. Data of Judicial Statistics]. URL: http://www.cdep.ru/ index.php?id=79\&item=4476 (accessed 1 March 2018).

14. Tymchuk Yu.A. Novyy vektor razvitiya zakonodatelstva o gosudarstvennoy registratsii prav na nedvizhimost: ot bumazhnykh svidetelstv do blokcheyna [New Vector of Development of the Legislation on State Registration of the Rights to the Real Estate: from Paper Certificates to Blockchain]. Mezhdunarodnyy studencheskiy nauchnyy vestnik, 2017, no. 5. URL: http://eduherald.ru/ru/article/ view?id=17745 (accessed 8 September 2018). 
Ю.А. Тымчук. Инновационные подходы в правовом регулировании механизма государственной регистрации прав

\section{Information about the Author}

Yuliya A. Tymchuk, Assistant, Department of Civil and International Private Law, Volgograd State University, Base Department of the Southern Scientific Center of Russian Academy of Sciences, Prosp. Universitetsky, 100, 400062 Volgograd, Russian Federation, gimchp@volsu.ru; yuliannatymchuk@yandex.ru, https://orcid.org/0000-0002-0854-3179

\section{Информация об авторе}

Тымчук Юлия Александровна, ассистент кафедры гражданского и международного частного права (базовой кафедры ЮНЦ РАН), Волгоградский государственный университет, просп. Университетский, 100, 400062 г. Волгоград, Российская Федерация, gimchp@volsu.ru; yuliannatymchuk@yandex.ru, https://orcid.org/0000-0002-0854-3179 